NOTAS

\title{
CAUTIVOS EN LAS APARIENCIAS. LA HISTORIA, SUS FINES Y SUS MUERTES
}

Boris Berenzon*

\begin{abstract}
RESUMEN: ¿Otra crisis cultural? El sujeto es un efecto del conflicto entre el univocismo y el equivocismo, entre un mundo metafórico y uno metonímico, que tiende a la interpretación de la muerte del pasado con sus planteamientos filosóficos. Así, se ha construido la imagen del fin de la historia como una dialéctica histórica que demuestra, por eso mismo, que ésta no es posible.
\end{abstract}

PALABRAS ClaVE: historia, fin de la historia, filosofia de la historia, muerte del sujeto, crisis cultural.
ABSTRACT: Another cultural crisis? The person is the victim of a conflict between univocalism and equivocalism, a metaphorical and a metonymic world which holds the analysis of the death of one's past as one of its philosophical premises. Therefore, the image of the end of history is seen as a dialectic of history which shows that this is impossible.

KEYWORDS: history, end of history, philosophy of history, death of the subject, cultural crisis.

RECEPCIÓN: 12 de junio de 2008.

ACEPATACIÓN: 16 de diciembre de 2008.

* Facultad de Filosofía y Letras, UNAM. 


\title{
CAUTIVOS EN LAS APARIENCIAS. LA HISTORIA, SUS FINES Y SUS MUERTES
}

\author{
Muerte sin fin de una obstinada muerte, \\ sueño de garza anochecido a plomo \\ que cambia si de pie, mas no de sueño, \\ que cambia sí la imagen, \\ mas no la doncellez de su osadía.
}

José Gorostiza, Muerte sin fin.

\section{La muerte tiene permiso o "Hermes el engañoso"}

Las fisuras de la sociedad actual y sus constantes movimientos pendulares: económicos, culturales, científicos, tecnológicos y religiosos o místicos, fragmentan al sujeto, lo menguan y lo confinan a un ser solitario con normas $\mathrm{y}$ valores que no desea, para poner en constante reto al ser entre la "ética del deseo" con la "del deber ser". Así, el sujeto de nuestra época no puede interpretar a la sociedad en la que vive, ni su pasado, se automatiza y por ello se deshumaniza puesto que los papeles que desempeña son institucionalizados, constituyendo su única identidad su rol en el trabajo o el trabajo mismo. Es lo que hace y no el que es.
¿Una crisis cultural más? Sí, el sujeto es efecto del conflicto entre el univocismo y el equivocismo, entre un mundo metafórico y un mundo metonímico que tiende a la muerte del pasado; para evitar el efecto de boomerang se necesita la proporción.

Hans-George Gadamer ${ }^{1}$ señala que la virtud del hermeneuta es la

${ }^{1}$ Hans-Georg Gadamer, Verdad y método, 1997, Salamanca, Sígueme, tr. de Ana Agud y Rafael de Agapito, p. 205-255. Gadamer propone en su libro que el carácter relativamente involuntario e inconsciente del arte encuentra fundamento sólido en su carácter de juego, es una consecuencia del sometimiento a las condiciones propias del juego. Por lo que se refiere a la participación del lenguaje en el arte, no se contradice con su condición de gusto si se tiene en cuenta que, cuando el lenguaje interviene en el arte, no lo hace, como en el uso ordinario, en su calidad de instrumento con una finalidad preestablecida, sino como materia cuya manipulación según las reglas del juego artístico se dirige a nuevos fines. La escritura creativa sólo empieza a funcionar cuando las palabras 
phrónesis, la prudencia que no es más que la semejanza puesta en práctica; y que fue traducida como prudentia, deliberatio; todo lo que es propio de la phrónesis no es más que analogía puesta en juego, la capacidad de trascender los límites establecidos de la interpretación. Aristóteles ya lo decía en el Peri Hermeneias, que se ha traducido de muchas maneras: Sobre la interpretación, Sobre el juicio, Sobre el enunciado o la enunciación; así quedarán el tiempo y el espacio como genuinos horizontes de toda comprensión y de toda interpretación del ser.

Aristóteles señala que la verdadera interpretación se explica más allá del tratado de hermenéutica, no el Peri Hermeneias sino en Tratado de Retórica, propiamente, porque es toda la teoría de los tropos, más que el Peri Hermeneias que es un tratado de lógica sobre el juicio y poco penetrable, muy teórico y a veces inalcan-

se utilizan no en función de su estricto significado (en este caso forman un pobre registro de esquemas que sólo enuncian pensamientos muy simples) sino con arte, como hacen los malabaristas con los sombreros, los huevos y los pañuelos con una intención distinta de la de ponérselos, sorberlos o sonarse la nariz. Empleando las palabras de este modo podemos convertir su teclado en un instrumento transmisor de pensamiento fresco y cálido. Y este mecanismo no es sólo el de la poesía, como apunta Gadamer, sino el de las demás formas de arte, la pintura, el de la arquitectura, por ejemplo, utiliza a la vez los signos, los trazos y los colores no sólo en función de las figuras a las que se les atribuyen ( $y$ de forma tal que hay que tomarlas al pie de la letra), sino por el contrario, aplicándose por romper su vínculo tan inmediato con las representaciones directas de los objetos. zable. La teoría aristotélica, propiamente hermenéutica, se presenta en la retórica,

Para Aristóteles hay varios tipos de lógica: una que usando sus palabras aplicamos, que se puede llamar apodíctica $\mathrm{u}$, hoy, la llamada axiomáti$c a$. Es lógica analítica. En cambio, la otra es la lógica tópica o, como él la llamaba, dialéctica. La diferencia es muy importante: la lógica apodíctica es la lógica de la verdad necesaria, de los axiomas. Pero es muy poco lo que se puede trabajar en ella, mientras que la lógica tópica es la lógica argumentativa, la que explica en el libro de los tópicos y que es una verdad no necesaria, sino una verdad posible o, mejor dicho, plausible, y por ello vital; es en la que nos movemos todos los días y la que ha sido el pilar desde el cual se construyó el pensamiento hasta el estructuralismo, lo que le permitirá a Foucault decir que con la modernidad triunfó la semiótica, y entonces la hermenéutica tiene que desaparecer porque la semiótica, es la pretensión de cientificidad con respecto a los signos y los símbolos. La semiótica quiere ser unívoca y la hermenéutica equívoca. Siempre es el peligro de la muerte de la episteme, es decir, de una cultura en un momento dado, que defina las condiciones de posibilidades de todo saber, sea que se manifieste en una teoría o 
NOTAS

que quede silenciosamente en una práctica. $^{2}$

La sociedad de los semejantes, último reducto del sujeto, de su cultura, se encuentra en crisis al reducirse y nuclearse primero, para luego empezar a desestructurarse. El sujeto del pasado no es ya la condensación de virtudes sociales, de grupos, es sólo el individuo así, sin aparentes fisuras para la interpretación, la muerte del sujeto.

La cultura trata de salvarse creando nuevos mundos, nuevas propuestas culturales con otros solitarios diferentes dentro de grandes conjuntos sociales. Fracasa total o parcialmente, vuelve y se plantea la conciencia de sí mismo y se da cuenta de su aislamiento. Se distancia del mundo o lo enfrenta desde la contradicción general provocando la reacción de éste contra él: la agresión y la represión a su inconformismo que da la conciencia histórica. Esto obliga al historiador a volverse contra sí mismo, ajeno y encerrado contra esa realidad hostil; la modernidad líquida y la vida de consumo que nos plantea Zygmunt Bauman, ${ }^{3}$ en la medida en que lo social

${ }^{2}$ Michel Foucault, Las palabras y las cosas. 1985, México, Siglo XXI, trad. Elsa Cecilia Frost, p. 115.

${ }^{3}$ Zygmunt Bauman, Amor líquido. Acerca de la fragilidad de los vínculos humanos, 2005, Argentina, F.C.E.; Vida de Consumo, 2007, México, F.C.E., y Tiempos líquidos. Vivir en una época de incertidumbre, 2008, México, Consejo Nacional para la Cultura y las Artes y Tusquets Editores, trad.Carmen Corral Santos. enajenó al sujeto como producto, se negó a los procesos de la vida y por ende de la muerte, a la cual empezó a mirar con angustia, a temerle, a negarla y, en cierto modo, a silenciarse ante la evidencia de su no existencia, a pensar en su fin.

El sujeto ha sido el proceso histórico del sujeto histórico ante la muerte en los tres últimos siglos. Hoy no queda nada, ni el sentido que cada uno debe tener de su muerte inminente; el Nuncius Mortis ha desaparecido.

Es nuestra era pobre en la valoración de lo subjetivo, al acogerse a estas ideologías colectivas que destruyen la integridad del sujeto y el valor por la vida.

El ser, al verse considerado objeto entre varios objetos, sin ser sujeto para nadie, vive su abandono en una historia marcada por el analfabetismo y el pragmatismo histórico que es una muerte tácita del pasado que produce una angustia teórica y vital para reconstruir las coordenadas del tiempo y el espacio por su aislamiento existencial.

La muerte le significa al mundo de la historia su fin; las teorías acerca de ella son generalmente las diferentes opiniones sobre la vida. Freud, al considerar la ansiedad por la muerte, decía que nadie cree su propia muerte y el inconsciente de cada uno está convencido de su propia inmortalidad. 
El historiador actual muestra una patente inclinación a prescindir de la muerte, a eliminarla de su vida. Ha intentado silenciarla y la muerte propia le es inimaginable. ¿Y qué es la historia sin la conciencia de la muerte?

El historiador occidental, pragmático y "cientificista" ha querido reducir su temor a la muerte con la simple denegación, a través de la tecnología, a la cual se aferra en un sueño de inmortalidad. Ha construido palacios tecnológicos que lo alejan de sí mismo y le niegan, en gran parte, las experiencias de su proceso de morir, incluyendo la afectividad social.

A su vez, ha permitido, tolerado e impulsado que la vida y la muerte se desplacen de lo moral a lo tecnológico y, más grave aún, a la sociedad de consumo; "El nuevo imperialismo", del que nos habla David Harvey, ${ }^{4}$ ha perdido el significado de su existencia y de su muerte, pulverizando su identidad, sus estructuras afectivas y su pensamiento. Se niega toda posibilidad de vivir y morir, simplemente se aniquila.

Los historiadores pasamos mucho tiempo en compañía de los muertos y cavilando sobre la muerte. La muerte atraviesa la interpretación histórica. ${ }^{5}$ Podremos dilucidar ese sentido para

\footnotetext{
${ }^{4}$ David Harvey, El nuevo imperialismo, 2003, Madrid, Akal, trad. Juan Mari Madariaga, p. 50.

${ }^{5}$ Philippe Aries, El hombre ante la muerte, 1983, Madrid, Taurus, trad. M. Armino, p. 156-90. Aries ha mostrado en este libro que es (im)posible escribir la historia de las milenarias relaciones del hombre de Occidente con la muerte.
}

trascender cómo la humanidad se relaciona con la muerte o cómo el sujeto labra el semblante de la muerte. ${ }^{6}$

Los principales enfoques históricos crean un imaginario profuso de la muerte frente a otros momentos históricos. ${ }^{7}$ Durante el barroco ${ }^{8}$ se celebraba a la muerte; no se comprendería esta actitud sin recordar que ella estaba formada por la fe en el más allá. El barroco narra, no el triunfo de la muerte, sino el triunfo sobre la muerte. La oposición con la muerte masiva y repentina, ocasionada por la peste, dio origen al impulso de una abierta temática en torno a lo fúnebre y lo macabro, en la que sólo se manifestaba el miedo hacia la flaqueza de la vida y lo imprevisto de la muerte. Se representó en varios grabados, entre ellos los de las Ars Moriendi, que ayudaban al bien morir. La literatura para salvar el alma es el conjunto de impresos y manuscritos que hicieron

${ }^{6}$ Alrededor de 1968, la muerte se convirtió en tema de punta de la historia francesa contemporánea. Esta nueva historia de la muerte, como la llamó Emmanuel Le Roy Ladurie, adoptó un punto de vista antropohistórico.

${ }^{7}$ Jesús Ángel Ochoa, Muerte y Muertos. Culto, servicio, ofrenda y humor de una comunidad, 1974, México, SEP, 168 p. Ochoa nos señala que en ese sentido no deja de ser interesante la conformación que se da, por ejemplo en México, sobre el día de muertos, tradición sincrética en la que finalmente el festejo es un diálogo entre la vida y la muerte, trascendiendo la visión sesgada de Octavio Paz de que los mexicanos se ríen de la muerte.

${ }^{8}$ Bolívar Echeverría, La modernidad de lo barroco, 1998, México, ERA-UNAM, p. 185. 
de la vida una constante preparación para la muerte. Dos principales grupos de obras comparten esta historia: las obras de carácter funerario, como los libros de exequias y las oraciones fúnebres, y los libros del bien morir. La misión de los libros del bien morir residía en apuntalar a los cristianos a tener una vida ejemplar para poder llegar a la muerte en un estado ideal de santidad, además de apoyar el tejido social de la Iglesia a partir de la Contrarreforma y fortalecer su poder eclesiástico, puesto en riesgo desde la segmentación del cristianismo por los protestantes.

Creencias, imaginarios y pulsiones se alimentan de la muerte y del significado y significantes que se le atribuyen, ya se trate de su propia muerte, del prójimo, o aun la de la filosofía de la historia, una teoría social sobre el pasado. Un repertorio de gestos y actitudes, de símbolos y contenidos en torno a la muerte son la memoria de pasajes de la relación del historiador y su entorno epistemológico. En el tema de la muerte naufragan las metodologías establecidas, los enunciados a priori y a posteriori. El historiador tendrá, pues, que construir su objeto y los medios para aproximarse al tema de la muerte. La originalidad y el valor de la historiografía surgen también de la forma como está construido el pensamiento.
¿La muerte de la historia? ¿Será la transfiguración de su vitalidad o el deseo de su fin? Se trata de analizar e interpretar, sin paráfrasis ni decodificación precipitada, el sentido de los fines de la historia. Es reconocer la "solidez de las palabras y de las cosas" y la "resistencia de lo visible", según Jacques Rancière, ${ }^{9}$ quien advierte contra la tentación de suponer que "las imágenes están para transmitir mensajes y disimular realidades" y pretender leer en ellas, de golpe, algo distinto de lo que dicen simplemente. Se trata del transcurso del tiempo y el espacio, asunto primordial para todo historiador, que forma su motivo vital.

El propio Heidegger no advierte que el peligro de este tiempo es que la verdad se reduzca a lo exacto, a lo medible y lo cuantificable. Lo unívoco es la técnica y el funcionalismo; lo toleramos a diario, lo vivimos como la muerte de la dialéctica, la que fragmenta al sujeto de la historia, lo empequeñece y lo confina a un ser solitario con pautas y valores que no comprende. No puede manejar la sociedad en que vive, pierde la dialéctica de la pasión y se deshumaniza, puesto que los papeles que desempeña son institucionalizados en una cosmovisión filo-

${ }^{9}$ Jacques Rancière, El odio a la democracia, 2006, Buenos Aires, Amorrortu, trad. Irene Agoff, p. 103-15. 
sófica, constituyendo su única identidad. Así, emergen en todos los tiempos los llamados fines o muertes de la historia.

La sociedad de los semejantes, último reducto de su todo, de su cultura, se encuentra en crisis al reducirse y nuclearse primero, para luego empezar a desestructurarse. El sujeto del pasado no es ya la condensación de virtudes sociales, de grupos, es sólo él. El sujeto trata de salvarse, muriendo para renacer, ${ }^{10}$ creando nuevos mundos, nuevas propuestas culturales con otros solitarios sujetos diferentes dentro de grandes conjuntos sociales. Fracasa total o parcialmente, vuelve y se plantea la conciencia de sí mismo y se da cuenta de su aislamiento. Se distancia del mundo o lo enfrenta contradictoriamente, provocando la reacción de éste contra él: ahí nace la agresión y la represión a su inconformismo que produce la conciencia histórica.

En la medida que lo social, la falta de conciencia histórica, enajenó al individuo desde el cientificismo, éste negó los procesos de la vida y por ende de la muerte, a la cual mira con angustia y temor, y por ello la niega silenciándose ante la evidencia de su no existencia, el pensar en su fin.

El historiador llega a perder el significado de su existencia y de su

${ }^{10}$ Slavoj Zizek, El acoso de las fantasías, 2007, México, Siglo XXI, trad. Clea Braunstein Saal, p. 43-119. muerte, pulverizando su identidad, sus estructuras afectivas y su pensamiento. Se niega toda posibilidad de vivir y morir; simplemente se aniquila en nombre de la añeja e imaginaria objetividad.

Por otro lado, las culturas no occidentales poseen sistemas filosóficos y religiosos, cosmologías, rituales y ciertos elementos de organización que facilitan la aceptación social de la experiencia de la muerte. Por lo general, estas culturas no ven la muerte como un fin absoluto de su existencia; creen que la conciencia o alguna forma de vida continúa después de la muerte biológica: la muerte es una transición o transfiguración y no una aniquilación.

La historiografía ha llegado a este ciclo como causa del ser humano carente de sensibilidad, entregado a la modernidad. La historia puede asumir a la muerte como un proceso vivificante, alejado del temor, la culpa y el castigo. Para la historia, regresar a la muerte original es volver a la vida de antes de la vida, a la vida de antes de la muerte: al halo, a la entraña de su existencia.

Muerte sin fin, el poema de José Gorostiza, es quizá el más alto testimonio que poseemos los hispanoamericanos de una conciencia verdaderamente moderna, inclinada sobre sí misma, presa de sí, de su propia claridad cega- 
NOTAS

dora. El poeta, al mismo tiempo lúcido y exasperado, desea arrancar su máscara a la existencia, para contemplarla en su desnudez. El diálogo entre el mundo y el hombre, viejo como la poesía y el amor, se transforma en el del agua y el vaso que la ciñe, el del pensamiento y la forma en que se vierte y a la que acaba por corroer. Como señala Octavio Paz: "Preso en las apariencias -árboles y pensamientos, piedras y emociones, días y noches, crepúsculos, no son sino metáforas, cintas de colores-" el poeta advierte que el soplo que hincha la sustancia, la modela y la erige forma, es el mismo que la carcome y arruga y destrona. En este drama sin personajes, pues todos son nada más reflejos, disfraces de un suicida que dialoga consigo mismo en un lenguaje de espejos y ecos, tampoco la inteligencia es otra cosa que reflejo, forma, y la más pura, de la muerte, una muerte enamorada de sí misma.

La ya desgastada frase, lugar común, "los pueblos que ignoran su historia están condenados a repetirla" evoca la dúctil moral de los historiadores seguidores de Cicerón, quienes piensan que la historia enseña sólo una de las caras de Jano, y no hacen eco del doble mensaje de Cicerón quien dice que la historia nos enseña lo bueno y lo malo del pasado, su memoria pero también su eco. "Los pueblos que ignoran su historia están condenados a repetirla." Esta frase está sintomáticamente a la entrada del Museo de los Horrores que los vencedores de la Segunda guerra mundial instauraron para cobijar sus culpas en el campo de Dachau, en Baviera. "Repitamos la historia, antes de que se nos olvide" responden otros sujetos más pragmáticos y cínicos, que eluden el sentido del conocimiento histórico y sus consecuencias. “¿Dime para qué me recuerdas?", dicen los más escépticos, dudosos de que Clío cumpla los anhelos de Cicerón.

Quizás como estas interrogantes, se hayan dado las llamadas muertes de la historia que tienen varios puntos álgidos; pensemos en la era de los griegos y los romanos, la Edad Media, San Agustín y Santo Tomás, el fin de la historia para Hegel y Marx, Schleiermacher, Dilthey, Heidegger, Gadamer, Arendt y recientemente las propuestas del imperialismo tardío en Francis Fukuyama y Samuel Huntington, quienes inventan nuevos finales de la historia para justificar, sin ética histórica, el nuevo desorden mundial.

La tarea filosófica parece haber tenido desde sus inicios griegos una clara predilección por la ahistoricidad, o bien, por una historia cíclica con fines y principios, muertes y nacimientos. $\mathrm{O}$, más bien, cabría decir que la búsqueda filosófica se interesó por los aspectos atemporales e inmuta- 
bles de lo real y por ende relegó, cuando menos, a un lugar secundario lo histórico.

En este sentido, matar el tiempo parece haber sido la ocupación preferida de los filósofos y de los sabios en general. Las características de este período son también las notas definitorias de lo verdadero y, por tanto, los caracteres de la ciencia, de la episteme. Con el pensamiento platónico, lo temporal e histórico, lo cambiante, quedó no sólo fuera del ámbito del verdadero saber, sino también fuera de la verdadera realidad. Lo histórico, lo cambiante, forma parte de la apariencia engañosa, es característico de la maldad de este mundo de sombras, mundo malo en cuanto aparente y cambiante $y$, por tanto, engañoso.

La historia no es un conocimiento tradicional, ni quiere serlo en ese contexto. Pues sólo puede haber epistemología acerca de lo permanente, de lo inmutable, de las formas arquetípicas eternas.

Estos arquetipos suelen caracterizarse, desde la concepción clásica griega de la temporalidad, como una concepción cíclica, y oponerla en cuanto tal a la concepción judía o cristiana del tiempo, concepciones que se caracterizan a su vez por la linealidad. Esto no es del todo exacto; en primer lugar, porque no puede decirse que existiera una única concepción griega acerca del tiempo; y, en segundo, porque incluso existen concepciones lineales del tiempo entre los griegos. Finalmente, porque la llamada concepción cíclica tenía para los diversos autores griegos significaciones diferentes. Pero de modo general puede aceptarse la contraposición, al menos, en el sentido en el que se pretende utilizarla. Pues si bien es así, sin embargo el predominio de lo atemporal es claro en toda la trayectoria filosófica occidental. Además, el pensamiento griego está primariamente encaminado a la comprensión del mundo y la naturaleza física, y ésta es caracterizada como ahistórica.

En este aspecto, el contraste con la forma de pensamiento bíblica difícilmente podrá negarse. Se ha llamado a los judíos constructores del tiempo. La definición es básicamente correcta y fundamentalmente idónea para trazar su concepción original de una temporalidad lineal que se articula en una historia con un principio, un final y una finalidad.

El cristianismo heredó, pero desarrolló en forma autónoma, esta concepción bíblica judía, concibiendo un tiempo lineal, marcado por los signos de Cristo y pleno de una tensión oculta que dota a la historia de un específico contenido de salvación y de una densidad dramática especial. Hay que añadir a continuación que ese sentido, densidad y finalidad de la historia de muerte y salvación no son parte de la historia misma, sino que depen- 
NOTAS

den de lo que está fuera de ella. La finalidad que da sentido y orientación a la historia es precisamente la cancelación de la historia y de la temporalidad y la espacialidad en un nuevo mundo eterno, en una perpetuidad gozosa, ajena a la temporalidad del duelo y la muerte. Esta tensión entre lo temporal y lo eterno le da al tiempo y al espacio la manifestación de prescripción que conduce a la muerte. Sólo el poder de Dios, de lo eterno inmutable, salva de la muerte. Así, también en la visión cristiana la historia por sí misma es apariencia y, en último término, nada. Lo verdadero, lo existente, lo real es lo eterno. El predominio de la eternidad sobre el tiempo da lugar en la historia del cristianismo a tensiones distintivas que muestran un doble movimiento: la tendencia, por una parte, a la huida del mundo, a la negación de su valor; por otra, el mito del premio por el bien es aparentemente paradójico de las tareas terrenas, temporales, que se expresan en el interés por el hombre y por sus condiciones de vida, esto es, en una tendencia recurrente a la revolución social. Pero de nuevo hay que notar que la segunda tendencia, de valorización del mundo, tiene como fundamento básico no el mundo mismo sino el principio divino.

La versión del cristianismo en moldes de pensamientos neoplatónicos, al expandirse por el mundo greco- rromano, favoreció el relegamiento de lo terreno y de lo corporal, sede de la corrupción y de la temporalidad, en favor de lo eterno en el hombre y del fin de la historia, su propia construcción de la muerte. Emblemático es el pensamiento de San Agustín, tanto en el campo de la desvalorización de la materialidad y corporalidad, como en el campo de la concepción de la historia: lo decisivo es la construcción y expansión de la Ciudad de Dios frente a la Ciudad terrena. Ambas ciudades son dos concepciones del mundo, del hombre y de la historia, en pugna constante hasta la final abolición de una de ellas: la gran muerte de la historia porque es construida desde la metafísica.

\section{Las diversas figuraciones \\ de Thánatos en la historia}

Los hombres sólo se reconciliaron con la muerte para evitar el miedo que ella les inspira: sin embargo, sin ese miedo, morir no tiene el mínimo interés. Pues la muerte existe únicamente en él y a través de él. [...] Quien ha superado el miedo puede creerse inmortal; quien no lo conoce, lo es. Es probable que en el paraiso las criaturas desaparezcan también, pero no conociendo el miedo demorir, no morirían, en suma, nunca. El miedo es una muerte de cada instante.

E. M. Cioran 
Con la llegada de la modernidad surge el impulso de sustraer lo real de la temporalidad, por medio de una geometrización y matematización de la experiencia, que sustituye el mundo de la experiencia cotidiana por signos que pretenden abarcar la universalidad, incluidas la vida y la muerte, como lo señala Peter Gay ${ }^{11}$ en su libro Modernidad. El autor propone contestar desde los valores modernos si hay vida después de la muerte. Responde desde la estética, como ejemplo de construcción histórica que explica el sentido del goce de vivir y el placer de morir.

Con el desarrollo de la ciencia moderna y de las ciencias humanas surge la necesidad de replantearse las relaciones entre el pensar y el hacer la historia; se piensa e incluso se siente, que la sociedad está compuesta a un tiempo por los muertos y por los vivos, y que los muertos son tan significativos y necesarios como los vivos. La metrópoli de los muertos es el dorso del consorcio de los vivos o, más que el dorso, su perfil, intemporal en el análisis del pasado. ${ }^{12}$

${ }^{11}$ Peter Gay, Modernidad. La atracción de la herejía de Baudelaire a Beckett, 2007, Barcelona, Paidós, trad. Marta Pino, Antón Corrient, Carnen Artime y Eva Almazan, p. 421-63.

${ }^{12}$ Mauricio Beuchot, La filosofia y el lenguaje en la historia, 2000, México, UNAM, Instituto de Investigaciones Filológicas, Discurso de ingreso a la Academia Mexicana de la Lengua. Respuesta de Ramón Xirau.
Los posmodernos hablan de la posthistoria, es decir, un corte con las filosofías de la historia, las propuestas esencialistas, del adiós al fundamento, del fin de los metarrelatos. La reflexión se ha planteado en torno a la ruptura con los valores históricos de la modernidad y su tradición; se trata de una profunda metamorfosis del ideal inacabado de la modernidad. Una tendencia intenta desaparecer el carácter históricamente situado de la razón, y también las críticas pertinentes al idealismo hegeliano, así como el pensamiento de Dilthey, Husserl y Heidegger, y dibuja un nuevo paradigma del entendimiento histórico.

Según Habermas, una característica relevante de un pensamiento postmetafísico es la nueva caracterización de la razón como una crítica al idealismo hegeliano; la primera generación de discípulos de Hegel, como Feuerbach, Marx o Kierkegaard, reclaman la finitud del espíritu. Pero los otros hegelianos no lograron plasmar un nuevo concepto en este sentido, trazaban las puertas de la crítica radical de Nietzsche.

El adecuado concepto de razón situada se logró gracias a otro tipo de crítica. La subjetividad trascendental chocó con los presupuestos de las nuevas ciencias del espíritu. El historicismo y la filosofía de la vida pusieron la recreación de la vida en el lugar de la síntesis trascendental, y la lingüís- 
NOTAS

tica permitió que el mundo estuviera abierto para los sujetos. ${ }^{13}$ Ese mundo de la vida estructurado lingüísticamente se apoya sólo en la práctica de los procesos de entendimiento de una comunidad. De esta manera, el giro lingüístico apuntaló los medios conceptuales con qué analizar la razón situada y materializada en la acción comunicativa.

La traslación desde la filosofía de la conciencia a la filosofía del lenguaje nos sitúa fuera del ir y venir entre idealismo y materialismo, y ofrece la posibilidad de abordar el problema de la individualidad y el sujeto de la historia. Así, la filosofía de la autoconciencia tenía que enfrentarse a la seria objeción de que la autoconciencia no es un fenómeno originario, puesto que la espontaneidad de la vida consciente escapa a la forma de objeto, forma que ha de tomar cuando el sujeto cognoscente se vuelve sobre sí mismo. La lógica y la semántica asestan un golpe a la teoría del objeto. Los objetos intencionales no hacen justicia a la estructura proposicional de los estados de cosas. El naturalismo pone en duda la posibilidad de partir de la conciencia; las teorías de Freud y Saussure quebrantan el dualismo conceptual de la filosofía

${ }^{13}$ Boris Berenzon Gorn, Historia es inconsciente (La historia cultura: Peter Gay y Robert Darnton), 1999, San Luis Potosí, El Colegio de San Luis, p. 32-3. de la conciencia. Pero sólo el giro lingüístico ha procurado un fundamento metodológico a tales reservas.

Según Merleau-Ponty, la racionalidad, lo universal, han de ser fundados de nuevo en la evidencia precientífica de que hay un único mundo, y no en el derecho divino de una ciencia dogmática; fundados en esa razón anterior a la razón, implicada en nuestra existencia, en nuestro comercio con el mundo encarnado, percibido y con los demás seres. Es preciso reconocer, más acá o más allá de la imagen físico-matemática del mundo, un punto de vista, una visión filosófica del mundo, que es también la visión existente de los hombres. La respuesta que Einstein dio a Bergson, en su encuentro de 1922, le parece a MerleauPonty una muestra de la crisis de la razón. Dijo Einstein: "La cuestión es entonces la siguiente: ¿Es el tiempo del filósofo el mismo que el del físico? Pero el tiempo de los filósofos no existe". Einstein admitía que el tiempo vivido, el tiempo percibido está en la base de nuestras nociones de tiempo y que nos lleva a la idea de un tiempo único. Pero negaba que el tiempo vivido tuviera nada, que cada uno vive o ve. No hay base para extender a la totalidad del mundo nuestra noción intuitiva de simultaneidad. Para Merleau-Ponty, esto significa que el científico no reconoce más razón que 
la razón física, la razón científica. La tarea filosófica consistiría entonces en mostrar el suelo precientífico en el que nuestras nociones (también las científicas) se asientan y sobre el que adquieren sentido. La hipertrofia de la ciencia niega al olvido ese humus del que todo pensar se nutre.

El mundo vivido, en el que transcurre nuestra existencia, es el mundo concreto, real y verdaderamente existente. Cualquier construcción explicativa nace de él y en él, y por él se mide. Es el único mundo que hay antes de que lo convirtieran en eslogan publicitario: hay otros mundos, pero están en éste. Husserl lo llamó el mundo de la vida. Merleau-Ponty lo llamaba el mundo encarnado; ha sido llamado de muchas otras maneras. El mundo es una totalidad estructural de relaciones, acciones, reacciones y transformaciones. La interacción es la praxis, acción transformadora reflexionada. La praxis es la relación característica de los seres humanos.

El mundo vivido es común. Este hecho nos coloca, por sí mismo, fuera de la problemática de la conciencia y del sujeto constituyente. El mundo vivido es ya común en la percepción y es común en cuanto mundo hablado, donde se construye la vitalidad de la historia y su propia muerte. ${ }^{14}$

${ }^{14}$ Jean Allouch, Erótica del duelo en el tiempo de la muerte seca, 1998, México, Edelp, tr. de Silvio Mattoni. p. 152.
El mundo del logos es una modulación de mundo, el peculiar mundo humano en el que estamos. La sedimentación de lo ya hablado es la cultura, allí se teje el destino tanático de la historia. El mundo físico y el mundo filosófico son a su vez modulaciones explicativas del mundo hablado. Como lo son también el mundo mítico, el mundo religioso, el mundo de las instituciones sociales.

Desde un punto de vista diacrónico, llamamos historia a la evolución o al devenir de tales sistemas culturales. $\mathrm{O}$, dicho de otro modo, cada sistema cultural tiene entre sus elementos un modo de integrar los cambios producidos en su propio entramado de relaciones estructurales.

La muerte es uno de los imaginarios de mayor significación en la historia del ser y su principal principio de realidad. Desde el hombre de las cavernas hasta los mutantes generados por la tecnología de la sociedad postmoderna, ninguno ha podido escapar a su revisión existencial

Para el hombre occidental, el tema de la muerte se ha transformado en una tanatofobia, simplemente porque intenta agotar su realidad en la razón, olvidando que el cemento primigenio de la pregunta acerca de la muerte es la inmortalidad y allí la historia tiene una tarea fundamental en torno a la memoria y el olvido. 
NOTAS

La muerte es una de las dimensiones básicas del ser humano, el nacer y el morir son rasgos inherentes al hombre de la misma manera que el amar y el odiar; Freud señala que el inconsciente del hombre está compuesto de dos cargas instintivas básicas: el instinto de vida (Eros) y el instinto de muerte (Thánatos). Desde ese punto de vista nuestra vida transcurre, o bien fundada en el instinto de vida, o bien en el instinto de destrucción o de muerte; depende de nuestra riqueza social, pero también emocional que se funda en el vientre de la historia... finalmente para no morir la última verdad de la historia es el enigma.

La historiografía ha llegado a este ciclo, como causa del ser humano, ca- rente, aislada por el mundo tecnológico, "cientificista" y consumista, el cual lo ha alejado de los procesos del vivir y del morir. La historia puede asumir a la muerte como un proceso vivificante, alejado del temor, la culpa y el castigo; para la historia, regresar a la muerte original será volver a la vida de antes de la vida, a la vida de antes de la muerte. ¿Será acaso como La otra muerte de Borges?

¡Pobre Damián! La muerte lo llevó a los veinte años en una triste guerra ignorada y en una batalla casera, pero consiguió lo que anhelaba su corazón, y tardó mucho en conseguirlo, y acaso no hay mayores felicidades. 